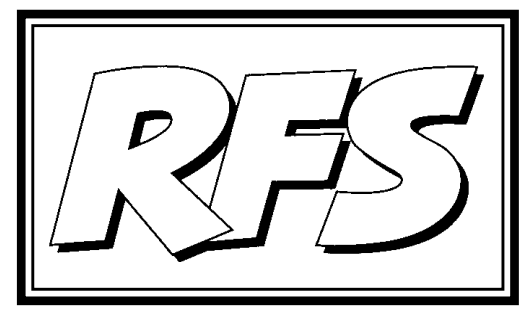

Revista de Fomento Social, 60 (2005), 313-328

\title{
El desarrollo socioeconómico de América Latina y el Caribe bajo el modelo multiexportador
} Antonio Luis HIDALGO CAPITÁN ${ }^{1}$

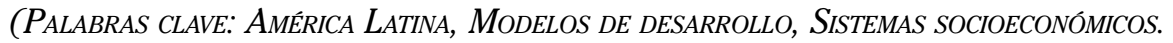

KEY WORDS: LATIN AMERICA, MODELS OF DEVELOPMENT, SOCIOECONOMIC SYSTEMS)

\section{Introducción ${ }^{2}$}

El presente trabajo pretende hacer un breve recorrido histórico por el funcionamiento de los sistemas socioeconómicos latinoamericanos (SSEL), deteniéndonos en particular en los últimos quince años, al objeto de poner

1 Universidad de Huelva (España). URL: http://www.uhu.es/antonio.hidalgo. E-mail: alhc@uhu.es

2 El presente documento fue presentado como Ponencia Invitada en la XVII Reunión de Directores de Cooperación Internacional de América Latina y El Caribe, organizada por el Sistema Económico Latinoamericano (SELA) en Caracas (República Bolivariana de Venezuela) entre el 2 y el 4 de mayo de 2005 . 
en perspectiva la reflexión sobre el desarrollo socioeconómico futuro de América Latina y el Caribe y las posibilidades de contribución de la cooperación internacional. No obstante, antes de comenzar debemos realizar algunas aclaraciones.

La primera tiene que ver con la pluralidad de América Latina y el Caribe. Es frecuente referirse a América Latina y el Caribe como una entidad más o menos homogénea, cuando en realidad estamos hablando de un grupo de países con dimensiones territoriales y poblacionales muy dispares, con estructuras productivas diferenciadas, con historias políticas diversas y con culturas diferentes. Sin embargo, a la hora de modelizar, en nuestro caso el funcionamiento de los SSEL, debemos encontrar características comunes a la mayoría de los países, que nos permitan definir un "sistema socioeconómico latinoamericano modelo", que, aunque no coincida en cada momento histórico con cada "sistema socioeconómico latinoamericano real", sí que sea al menos representativo de la mayoría de ellos ${ }^{3}$.

La segunda aclaración tiene que ver con los conceptos de "modelo histórico-estructural" y "modelo de desarrollo". Un modelo histórico-estructural es aquel modelo que representa el funcionamiento de un sistema socioeconómico durante un período largo de tiempo en el que su estructura permanece constante ${ }^{4}$; mientras que un modelo de desarrollo es aquel modelo que representa los pasos que debe seguir un sistema socioeconómico para transitar de un modelo histórico estructural a otro por medio de una transformación estructural, es decir, es un modelo de transformación estructural. En el caso de América Latina y el Caribe, excluidos los períodos precolombino y colonial, podemos distinguir tres modelos histórico-estructurales (el primario-exportador, el doméstico-industrial primario-exportador y el multiexportador) y dos modelos de desarrollo (el de industrialización por sustitución de importaciones y el reformista de ajuste estructural) ${ }^{5}$.

3 Los casos de Cuba, desde la revolución, de Nicaragua, durante el sandinismo y, tal vez, de Venezuela, desde la revolución bolivariana, se alejan bastante del análisis que sigue.

4 El concepto deriva de los planteamientos de SunKel y PAz (1970) y, en cierto modo, es equivalente a otros conceptos empleados por algunas corrientes de pensamiento, como el concepto cepalino de "estilo de desarrollo" (Graciarena, 1976; Pinto, 1976) o el concepto marxista de "patrón de acumulación" (Talavera, 1986; ValenZuela, 1986).

5 Es habitual utilizar la expresión "modelo sustitutivo de importaciones" o "modelo de sustitución de importaciones" para referirse a lo que nosotros denominamos "modelo histórico-estructural doméstico-industrial primario-exportador" -términos inspirados 


\section{Los modelos histórico-estructurales y los modelos de desarrollo lati- noamericanos desde la Independencia a nuestros días}

Para caracterizar de manera sintética los modelos histórico-estructurales latinoamericanos vamos a seguir un esquema, adaptado del utilizado por Talavera (1986), basado en el estudio de nueve aspectos de la estructura socioeconómica más el funcionamiento del sistema bajo este modelo. Dichos aspectos son: el tipo de producción; el destino de la producción; la articulación económica; la propiedad de los medios de producción; la financiación de la producción; el uso de los factores productivos; el papel del Estado; la distribución de la renta; y la estructura social. Por lo que se refiere al funcionamiento, lo relevante es el resultado de la interrelación entre los distintos aspectos anteriores (véanse detalles en Tabla 1).

Por su parte, la caracterización de los modelos de desarrollo latinoamericanos la realizaremos atendiendo a tres aspectos, el motivo por el cual surge, el objetivo que persigue y las políticas que lo conforman (véanse detalles en Tabla 2).

Teniendo todo esto en cuenta, podemos pasar a situar cronológicamente y a caracterizar los cinco modelos citados anteriormente:

- Desde la Independencia hasta la Segunda Guerra Mundial, el funcionamiento de la mayoría de los SSEL se basó en el modelo histórico-estructural primario-exportador (Talavera, 1986), caracterizado por el monocultivo de productos primarios de exportación, por un Estado de carácter liberal y por una sociedad dualizada (véanse detalles en Tabla 1).

\footnotetext{
en la expresión de Fallas (1983: 73), que llama al modelo adoptado en Costa Rica "agroexportador-industrial- sector público no planificado"-, así como "modelo de sustitución de exportaciones" para referirse al "modelo histórico-estructural multiexportador". Nosotros preferimos reservar las expresiones referentes a las políticas para los modelos de desarrollo, como "industrialización por sustitución de importaciones" y "reformista", como hacen algunos autores (EDWARDS, 1995; BULMER-ThOMAS, 1996). Así mismo, otros autores denominan al "modelo multiexportador" como "modelo secundario-exportador o de sustitución de exportaciones" (ANIMA y GUERRERO, 2003); si bien podemos aceptar la expresión "modelo secundario-exportador" para referirse a la concreción del dicho modelo en México, la expresión "modelo de sustitución de exportaciones" nosotros la reservaríamos como sinónimo de "modelo reformista", aunque ésta última nos parece más adecuada en cuanto que engloba a la propia sustitución de exportaciones. Sobre la aplicación de los conceptos de "modelos histórico-estructurales" y "modelos de desarrollo" al caso de Costa Rica, en el que se basa la tipología aquí utilizada, puede consultarse HIDALGO CAPTTÁN (2003).
} 


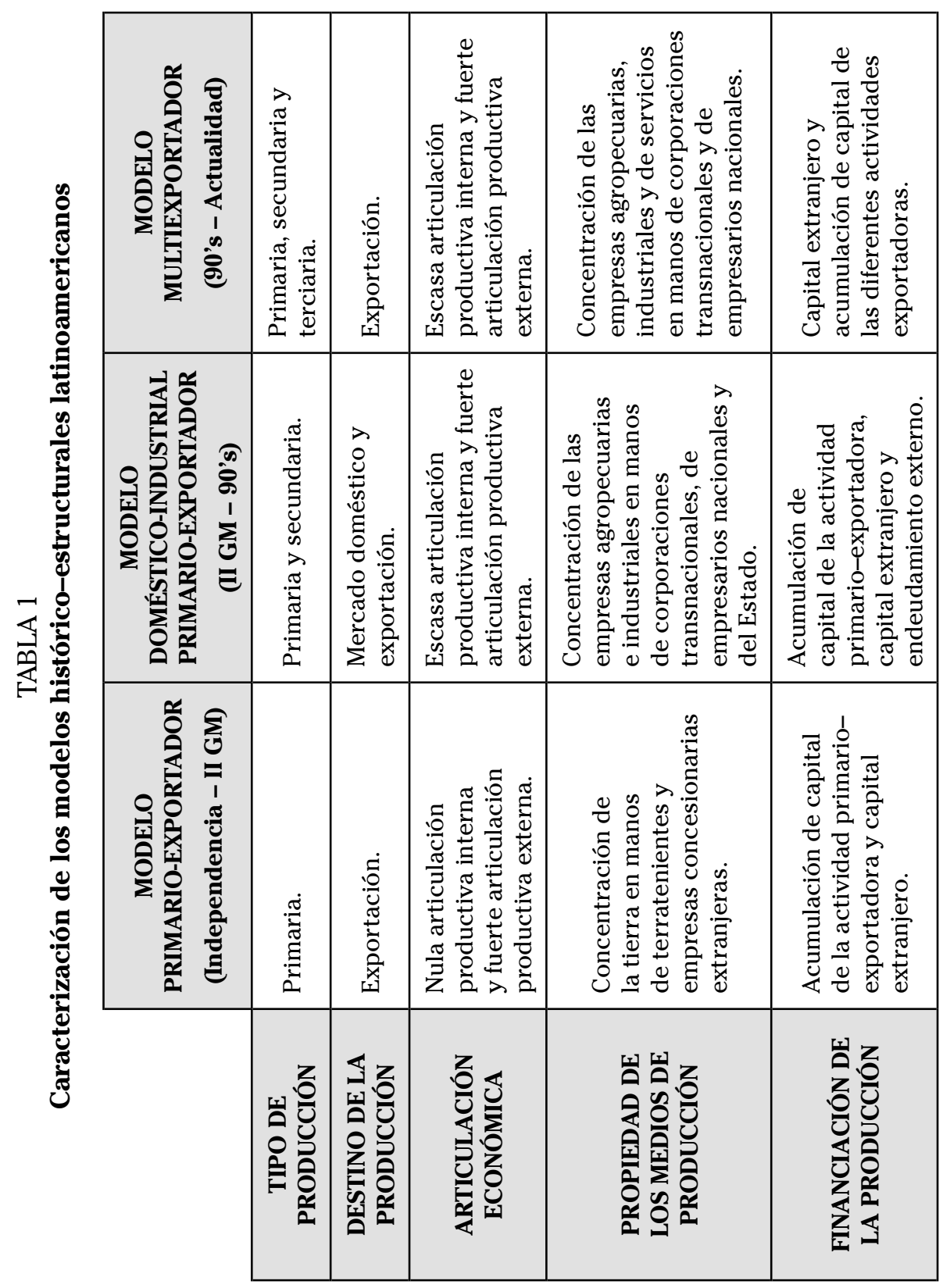




\begin{tabular}{|c|c|c|c|c|}
\hline 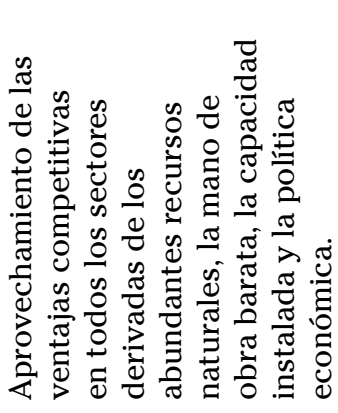 & 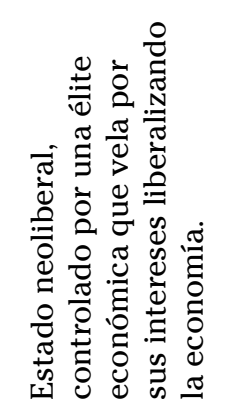 & 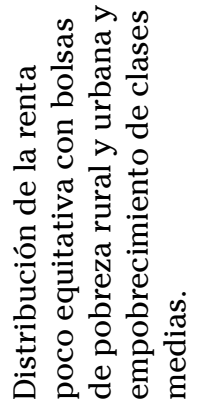 & 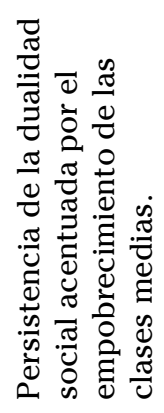 & 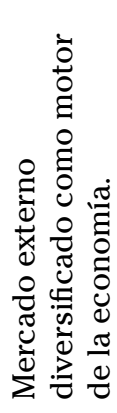 \\
\hline 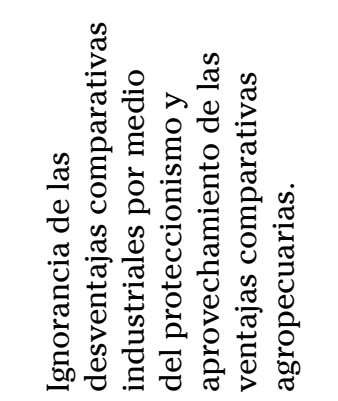 & 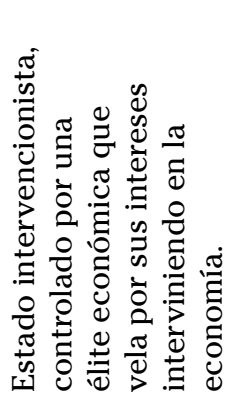 & 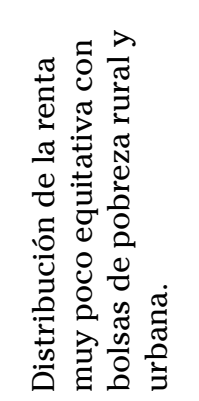 & 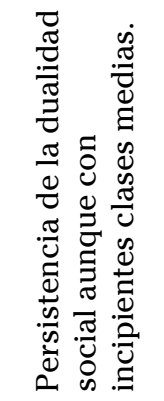 & 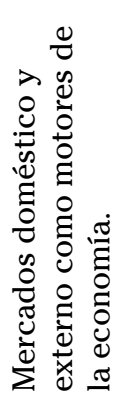 \\
\hline 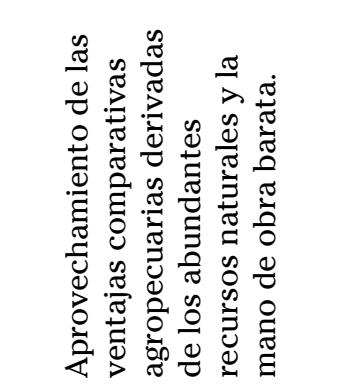 & 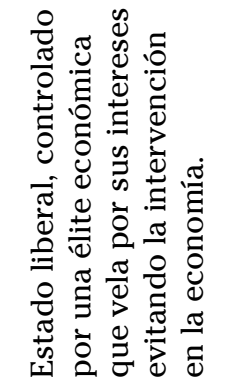 & 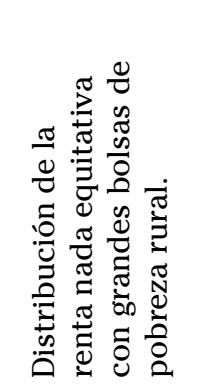 & 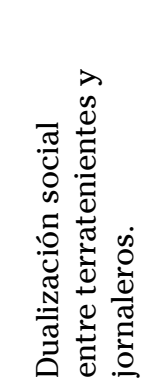 & 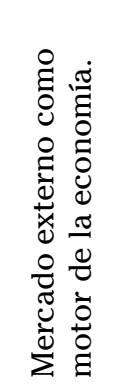 \\
\hline 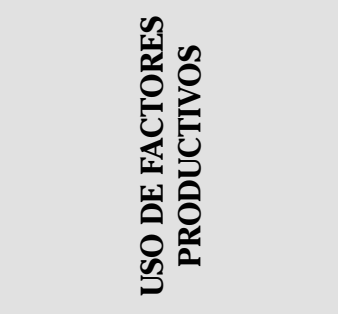 & 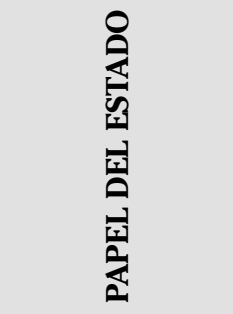 & 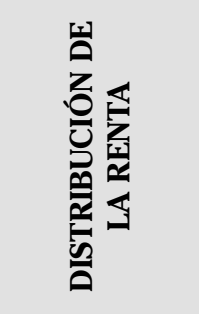 & 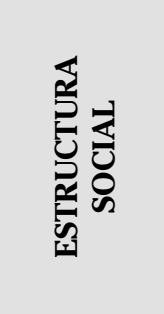 & 运 \\
\hline
\end{tabular}


- Dicho modelo se abandonó a raíz de la posibilidad de abastecer de productos manufacturados a los países desarrollados durante la II Guerra Mundial y de la toma de conciencia del deterioro de los términos de intercambio que generaba dicho modelo (Prebisch, 1949); y se hizo, durante las décadas de los cuarenta y cincuenta, por medio de la aplicación del modelo de desarrollo denominado de industrialización por sustitución de importación, basado en el desarrollo de una industria nacional protegida de la competencia y en la ampliación del mercado doméstico por medio de procesos de integración (véanse detalles en Tabla 2).

- Consecuencia de la aplicación de este modelo de desarrollo, en los SSEL se produjo una transformación estructural que hizo que el funcionamiento de los mismos fuese diferente al que venía siendo desde la Independencia. Entre la Segunda Guerra Mundial y principios de la década de los noventa del siglo XX, el funcionamiento de la mayoría de los sistemas socioeconómicos latinoamericanos se basó en el modelo histórico-estructural doméstico-industrial primario-exportador, caracterizado por el desarrollo de una producción industrial para el mercado doméstico, que coexistiría con una producción primaria para la exportación, por un Estado de carácter intervencionista y por la aparición de incipientes clases medias en medio de una sociedad aún dualizada (véanse detalles en Tabla 1).

- Este modelo se abandonó a raíz de la crisis estructural que sufrieron los SSEL durante la llamada "década perdida", cuyo detonante fue la declaración generalizada de moratoria en el pago del servicio de la deuda externa por parte de aquellos. En el contexto de dicha crisis se empezó a implementar un nuevo modelo de desarrollo denominado reformista y basado en la estabilización macroeconómica y el ajuste estructural neoliberal (Edwards, 1995; Bulmer-Thomas, 1996) (véanse detalles en Tabla 2).

- Consecuencia de la aplicación de este modelo de desarrollo, en los SSEL se produjo una nueva transformación estructural que hizo que el funcionamiento de los mismos volviese a cambiar. Así, desde principios de la década de los noventa y hasta la actualidad, el funcionamiento de la mayoría de los SSEL se basa en el modelo histórico-estructural multiexportador, caracterizado por la producción de una diversidad de bienes y servicios destinados a la exportación, por un Estado de 
carácter neoliberal y por el empobrecimiento de las clases medias en medio de una sociedad que sigue estando dualizada (véanse detalles en Tabla 1).

TABLA 2

\section{Caracterización de los modelos de desarrollo latinoamericanos}

\begin{tabular}{|c|c|c|}
\hline & $\begin{array}{c}\text { MODELO DE } \\
\text { INDUSTRIALIZACIÓN } \\
\text { POR SUSTITUCIÓN DE } \\
\text { IMPORTACIONES } \\
\text { (Años 40's - 50's del siglo XX) }\end{array}$ & $\begin{array}{c}\text { MODELO REFORMISTA } \\
\text { DE AJUSTE ESTRUCTURAL } \\
\text { (Años 80's-90's del siglo XX) }\end{array}$ \\
\hline MOTIVO & $\begin{array}{l}\text { Abastecimiento de países } \\
\text { desarrollados durante la II GM } \\
\text { y la toma de conciencia del } \\
\text { deterioro de los términos de } \\
\text { intercambio. }\end{array}$ & $\begin{array}{l}\text { Crisis estructural provocada } \\
\text { por la caída de las demandas } \\
\text { externa e interna y por el } \\
\text { aumento del servicio de la } \\
\text { deuda externa. }\end{array}$ \\
\hline OBJETIVO & $\begin{array}{l}\text { Sustituir las importaciones de } \\
\text { manufacturas por productos } \\
\text { industriales nacionales para } \\
\text { evitar el deterioro de los } \\
\text { términos de intercambio. }\end{array}$ & $\begin{array}{l}\text { Aumentar la competitividad de } \\
\text { la producción nacional para } \\
\text { captar las divisas necesarias } \\
\text { para pagar la deuda y reactivar } \\
\text { la economía. }\end{array}$ \\
\hline \multirow{5}{*}{ POLÍTICAS } & $\begin{array}{l}\text { Fomento de una industria } \\
\text { de producción de bienes de } \\
\text { consumo. }\end{array}$ & $\begin{array}{l}\text { Estabilización } \\
\text { macroeconómica. }\end{array}$ \\
\hline & $\begin{array}{l}\text { Apoyo a la producción } \\
\text { primario-exportadora. }\end{array}$ & $\begin{array}{l}\text { Promoción de exportaciones y } \\
\text { apertura comercial y financiera. }\end{array}$ \\
\hline & Proteccionismo comercial. & $\begin{array}{l}\text { Reforma del Estado y } \\
\text { privatización de empresas } \\
\text { públicas. }\end{array}$ \\
\hline & Integración regional. & $\begin{array}{l}\text { Flexibilización del mercado de } \\
\text { trabajo }\end{array}$ \\
\hline & $\begin{array}{l}\text { Intervención generalizada en } \\
\text { la economía. }\end{array}$ & $\begin{array}{l}\text { Liberalización del sistema } \\
\text { financiero. }\end{array}$ \\
\hline
\end{tabular}




\section{Características actuales de los SSEL: un análisis del modelo multiex- portador.}

Como indicábamos en el apartado anterior, el funcionamiento de la mayoría de los actuales SSEL responde al modelo histórico-estructural que hemos denominado multiexportador. Dicha denominación obedece a que el motor del modelo lo constituyen las exportaciones de diversa naturaleza, tanto agropecuarias como industriales o de servicios ${ }^{6}$.

Las características estructurales básicas de un sistema socioeconómico para que pueda ser interpretado por medio del modelo multiexportador, para lo cual seguiremos el esquema adaptado del de Talavera (1986), serían las siguientes:

- Los monocultivos primarios de exportación (café, banano, maíz, soja, azúcar, carne, cobre, estaño, petróleo...) y los sectores modernos, con alta productividad e intensivos en mano de obra (componentes mecánicos, eléctricos y electrónicos, productos agroindustriales y textiles, ensamblaje de manufacturas, turismo, teleservicios...), constituyen el grueso de la producción nacional, siendo el resto generado por los sectores tradicionales agropecuarios (granos básicos...), industriales (algunos productos de consumo no duradero) y servicios (comerciales, financieros, personales...) caracterizados, en general, por una baja productividad.

- La mayor parte de la producción agropecuaria, extractiva y manufacturera, y una parte de los servicios, se destina hacia el mercado externo, satisfaciéndose la demanda interna con algo de producción nacional tradicional y, sobre todo, con importaciones, generalmente de escasa calidad, que compiten con dicha producción.

- Existe una escasa articulación entre los dos sectores, el tradicional y el moderno, mientras que el sector moderno sí presenta una importante

6 No obstante, conviene hacer algunas aclaraciones. En primer lugar, Cuba es caso aparte por las particularidades de su estructura social, por el papel del Estado en la economía y por su peculiar inserción internacional. Y en segundo lugar, las exportaciones de algunos países presentan una fuerte especialización sectorial, como son los casos de México (manufacturas), Belice, Bolivia, Chile, Ecuador, Nicaragua, Panamá, Paraguay, Perú y Venezuela (productos primarios, incluido petróleo y otros recursos naturales) o Barbados y Bahamas (servicios, esencialmente turismo); esto hace que, aunque estos SSEL puedan ser caracterizados por medio del modelo multiexportador, su grado de vulnerabilidad sea mayor por la escasa diversificación de sus exportaciones. 
articulación con otros sectores de terceros países; ejemplos de articulación externa son las plantaciones y las haciendas, las zonas francas (maquilas) y los complejos hoteleros, que funcionan como auténticos enclaves agropecuarios, industriales y de servicios, que importan casi todas las materias primas, los bienes intermedios y los bienes de capital que utilizan en su producción, demandando, en muchos casos, sólo mano de obra nacional barata.

- La propiedad de las diferentes empresas agropecuarias, industriales y de servicios está repartida entre empresarios nacionales y extranjeros, aunque los sectores más dinámicos se encuentran en manos del capital extranjero (empresas transnacionales) o de capital nacional asociado a grupos empresariales extranjeros (crédito, tecnología, franquicia...).

- El excedente generado por las exportaciones agropecuarias, industriales y de servicios, se lo apropian las empresas transnacionales, los distribuidores extranjeros de la producción nacional, los empresarios nacionales de diferentes sectores y el Estado (que utiliza una gran porción de sus ingresos para el pago de la deuda externa).

- El aprovechamiento de las ventajas competitivas, a la hora de elegir las actividades económicas más rentables, supone: en primer lugar, la explotación intensiva de los abundantes recursos naturales y ambientales de esos países; en segundo lugar, la explotación intensiva de una mano de obra, que se mantiene barata gracias al control salarial del Estado; en tercer lugar; la utilización de la capacidad instalada (infraestructuras, capital humano...) derivada de la antigua política de industrialización por sustitución de importaciones; en cuarto lugar, el disfrute de los beneficios derivados de la política neoliberal del Estado (legislación fiscal y laboral laxa, frecuente devaluación competitiva del tipo de cambio...).

- Las funciones del Estado neoliberal son, por este orden: garantizar las condiciones necesarias para el adecuado funcionamiento del mercado (estabilidad macroeconómica, marco jurídico-institucional que garantice el derecho de propiedad privada y de libre contratación de mercancías y factores...); eliminar las distorsiones internas y externas (privatizaciones de empresas públicas, desregulaciones de sectores, eliminación de las barreras arancelarias y no arancelarias, apertura de la cuenta de capitales...); y redistribuir una parte del excedente que se apropia para garantizar la paz social (educación, sanidad...). 
- La distribución de la renta es ahora más equitativa que bajo modelos anteriores, pero no tiende a mejorar de forma significativa (pese al aumento de la renta per cápita y la reducción de los niveles de indigencia y de pobreza), ya que el deterioro de los niveles de vida de las clases medias, junto con el enriquecimiento de algunos sectores empresariales, impiden que la desigualdad continúe reduciéndose.

- Bajo este modelo surge el fenómeno de la exclusión social, que va más allá de la simple pobreza y que es consecuencia del abandono de determinadas funciones sociales que antes realizaba el Estado (pensiones, viviendas, gratuidad de determinados servicios públicos, transferencias de rentas...). Destaca también el aumento de la informalidad laboral (sobre todo en la producción destinada al mercado doméstico) y la reducción de la proporción de empleados públicos como consecuencia de las restricciones presupuestarias. El mercado de trabajo se encuentra dualizado entre nuevos profesionales, altamente cualificados y con elevados niveles de retribución, y trabajadores precarios, sin cualificación y con escasos ingresos. Además, el proceso de pauperización de las clases medias amenaza con generar una fractura social importante.

- El funcionamiento de este modelo se basa en el tirón del mercado internacional. Al ser la estructura socioeconómica muy dependiente del sector exterior, como único motor de la economía, la expansión de la economía internacional explica la expansión de las economías nacionales, mientras que las recesiones internacionales se traducen en profundas crisis económicas nacionales; sin embargo, este motor externo puede caracterizarse como un motor multiválvulas, ya que los riesgos están diversificados en un gran número de producciones exportables, por lo que las coyunturas sectoriales tienen menos influencia en el funcionamiento de este modelo que en el caso del primario-exportador basado en el monocultivo. La estabilidad del crecimiento bajo este modelo depende de una adecuada combinación de productos exportables.

No obstante, a pesar de que el modelo multiexportador ha permitido a la región recuperar niveles de crecimiento económico muy aceptables y que la inmensa mayoría de los SSEL presenta hoy día mejores niveles de desarrollo humano que hace tres décadas, lo cierto es que el nivel medio de desarrollo de la América Latina y el Caribe la sitúa como una región de desarrollo humano medio (IDH de 0,777 ), en la que sólo 11 países califican como de desarrollo humano alto (IDH superior 0,800) (PNUD, 2004). Veamos pues cuáles son las principales fallas de este modelo. 
- La competitividad de las exportaciones latinoamericanas es en su mayoría espuria (CEPAL, 1990), ya que se encuentra basada: en la explotación de recursos naturales, no sustentable ecológicamente, por cuanto su explotación sobrepasa la capacidad natural de renovación o agota las reservas existentes, además de deteriorar los ecosistemas circundantes en el proceso de extracción; en el mantenimiento de bajos salarios, que empobrece a los trabajadores y que no se sostiene a largo plazo, en la medida en que otros países con menos nivel de desarrollo siempre pueden ofertar mano de obra aún más barata; en una política cambiaria de permanente devaluación, que empobrece a los consumidores de productos importados y perjudica la producción nacional para el mercado doméstico que importa insumos; y en una política fiscal muy laxa respecto de las inversiones extranjeras (zonas francas, contratos de turismo, exenciones fiscales...), que reduce los ingresos del Estado, limitando presupuestariamente sus actuaciones y subvencionando así los presupuestos públicos de los países desarrollados donde tributan las empresas transnacionales por los beneficios obtenidos en América Latina y el Caribe.

- Como consecuencia de la estrategia competitiva, las exportaciones se basan en mercancías y servicios de bajo valor agregado y bajo contenido tecnológico, cuyo intercambio por bienes y servicios de elevado valor agregado y elevado contenido tecnológico genera una nueva forma de deterioro de los términos de intercambio, apenas compensada por las exportaciones petroleras (CEPAL, 2004-b: 358). El bajo valor agregado es debido a la escasa retribución del factor trabajo y la escasa articulación productiva de las actividades exportadoras, que no demandan otras producciones nacionales, sino insumos extranjeros. Por su parte, el mantenimiento de los salarios en niveles tan bajos favorece la apropiación del excedente generado en la región por la vía comercial (por ejemplo, un pantalón que se vende a 50 \$ en EEUU, es comprado por el propietario de la marca a una maquiladora dominicana por $3 \$$, de los cuales $1,5 \$$ son costes de insumos importados, $1 \$$ es beneficio de los propietarios nacionales de la empresa y $0,5 \%$ son costes laborales; es decir, en este caso, sólo el 3\% del valor del producto se queda en el país en que se fabrica y sólo el $1 \%$ va a retribuir al factor trabajo).

- Los bajos salarios, mantenidos por la acción-omisión del Estado neoliberal, el escaso gasto público social de dicho Estado y el abastecimiento de la población con productos importados (más caros de lo necesario 
por las continuas devaluaciones), perpetúan la dualidad social, permiten la persistencia de la pobreza y empobrecen a las escasas clases medias; todo lo cual contribuye a que la movilidad social (paso de unas clases sociales a otras) siga siendo prácticamente imposible, lo que a su vez redunda en una fragilidad de las democracias de la región (pronunciamientos militares, estados de emergencia, levantamientos populares, grupos guerrilleros y paramilitares, renuncias forzadas de gobernantes...).

\section{Reflexiones en torno al desarrollo socioeconómico futuro de América Latina y el Caribe}

La actual inserción internacional de América Latina y el Caribe es hoy día más sólida que bajo modelos anteriores, aun así algunos SSEL deben seguir profundizando en la diversificación de sus exportaciones; cuantos más productos diferentes exporte un país, más estable será su crecimiento económico.

Pero el punto más débil del desarrollo latinoamericano sigue siendo el deterioro de sus términos de intercambio derivado de su estrategia competitiva. América Latina y el Caribe necesita evolucionar, siguiendo el esquema de Porter (1990: 674-701), desde la actual "economía impulsada por los factores" (mano de obra y recursos naturales) hacia una "economía impulsada por la inversión", por medio de una acumulación de capital que permita crear nuevas ventajas competitivas; para posteriormente, por medio de la asimilación de tecnología extranjera, pasar a una "economía impulsada por la innovación", en la que algunos sectores productivos latinoamericanos se conviertan en líderes mundiales.

Para ello la clave está en propiciar la acumulación de capital, tanto físico como humano, lo que pasa por la reinversión del excedente generado en la región, en lugar de permitir su extracción; y ello puede hacerse por dos vías, la financiera y la comercial. Por la vía financiera, por un lado, debieran eliminarse todas las exenciones fiscales y subvenciones de todo tipo que disfrutan las empresas dedicadas a la exportación (en particular, los regímenes de zonas francas, ya en proceso de extinción) de forma que las mismas tributen al Estado igual que cualquier otra empresa (impuesto sobre la renta, aranceles...); por otro lado, debería incentivarse la reinversión de los beneficios obtenidos por las empresas exportadoras, sean nacionales 
o extranjeras, destinándolos a aumentar la acumulación de capital físico y humano y a la aplicación y a la asimilación de nuevas tecnologías.

Por la vía comercial, la estrategia debe ser igualmente doble. Por un lado, es preciso que las empresas dedicadas a la exportación adquieran el mayor número de insumos dentro de los mismos países donde fabrican sus productos, de forma tal que se quede en dichos países una mayor porción del valor agregado del producto final; aquí es esencial el papel de un Estado concertador, que ponga en contacto a las empresas exportadoras con sus potenciales proveedores nacionales, incentivando la firma de acuerdos. Y por otro lado, es necesario elevar la retribución que reciben los trabajadores de las empresas exportadoras; se debe reformar el sistema de trabajo a destajo, en el que se cobra en función del número de piezas terminadas, y volver a la retribución por jornada laboral, con retribución especial en caso de horas extras; se debe aumentar el salario mínimo interprofesional, que sirve de referencia a las empresas exportadoras para fijar sus retribuciones; y se deben invertir recursos públicos en la formación del capital humano, para que los trabajadores aumenten su productividad, e incentivar a las empresas para que inviertan en la formación de sus trabajadores y en la incorporación de nuevas tecnologías que redunden igualmente en el aumento de productividad.

En el ámbito social dos son igualmente los aspectos clave a corregir, la reproducción generacional de la pobreza y el empobrecimiento de las clases medias. Por lo que se refiere al primero, es primordial luchar contra la pobreza que sufren millones de latinoamericanos, a pesar de los escasos recursos financieros con los que cuenta el Estado. Convertir a un adulto de clase baja en un adulto de clase media es realmente costoso y las probabilidades de éxito son pequeñas, pero convertir a un niño de clase baja en un adulto de clase media es una empresa factible.

La lucha contra la pobreza debe focalizarse en el aumento de las oportunidades de los hijos de los pobres ${ }^{7}$, garantizándoles un nivel de vida digno,

7 El concepto de "desarrollo humano" como "el aumento de las oportunidades de los individuos", se popularizó a partir de la publicación en 1990 por parte del PNUD del primer Informe sobre desarrollo humano, documento clave del pensamiento alternativo sobre desarrollo, que se caracteriza por la identificación del desarrollo con la reducción de la pobreza, en lugar de con el aumento de la riqueza, como han venido haciendo el resto de las corrientes de pensamiento económico sobre desarrollo, como son la modernización, el estructuralismo, el neomarxismo, el neoliberalismo y todos los antecedentes de la Economía del Desarrollo (HidAlgo CAPITÁN, 1998). 
una adecuada cobertura sanitaria y el acceso a todos los niveles educativos. El Estado debe invertir sus recursos en las escuelas de las zonas rurales y urbanas más deprimidas, para convertirlas en "centros de oportunidades para niños y jóvenes", en los que se escolarice a los hijos de los pobres (de forma gratuita y obligatoria, hasta los dieciséis años y durante la mayor parte del día, retirándolos del trabajo infantil) y a los cuales no sólo se les ofrezca educación y formación (uniforme y material escolar incluido), sino también tres comidas al día (aliviando la carga económica para sus familias) $\mathrm{y}$ atención sanitaria.

Ello debe ser complementado con una política de becas para el resto de la población y para todos los niveles educativos, graduando el esfuerzo financiero del Estado en función del nivel de renta de las familias, y permitiendo así un amplio abanico de ayudas al estudio. Lo cual también redundará en la mejora del nivel de vida de las clases medias, dado que les facilitaría el acceso a la formación y con ello aumentarían sus oportunidades; clases medias sobre las que también influiría el aumento de los salarios.

Frenar la reproducción generacional de la pobreza y aumentar las oportunidades de las clases medias, serían también formas de reforzar la estabilidad democrática de los sistemas políticos latinoamericanos.

\section{Una posible contribución de la cooperación internacional}

A partir de las reflexiones anteriores pueden hacerse algunas consideraciones sobre el papel de la cooperación internacional articuladas en tres ejes: la aplicación de determinadas medidas en los países desarrollados; la condonación condicionada de la deuda externa; y la captación de recursos financieros de ayuda al desarrollo.

Una excelente forma que tienen los países desarrollados de cooperar con el desarrollo de América Latina y el Caribe es incentivar la reinversión de los beneficios obtenidos en la región (o por operaciones con empresas de la región-maquila-) por las empresas con domicilio fiscal en sus territorios (incentivos fiscales, deducciones por acción social, reconocimientos de excelencia empresarial transnacional...); se trata de medidas no particularmente costosas para el Estado de dichos países que además constituirían un verdadero ejemplo de responsabilidad social corporativa además de revertir en la mejora de la imagen corporativa de dichas empresas. 
La condonación de la deuda externa que los países de la región mantienen con organismos internacionales y países desarrollados puede ser otra interesante forma de cooperación al desarrollo, siempre que los países deudores se comprometan a reinvertir de forma obligatoria todos los recursos financieros condonados en proyectos que aumenten las oportunidades de sus ciudadanos, y en especial en los relacionados con la no reproducción generacional de la pobreza, la educación y la atención sanitaria. Este tipo de medidas son más fáciles de comprender por las opiniones públicas de los países desarrollados que en muchos casos cuestionan la condonación de la deuda ante el temor de que los recursos liberados se destinen a gastos superfluos o militares.

La tercera vía sería la captación de recursos financieros y humanos procedentes de organismos internacionales, países desarrollados, empresas transnacionales y organizaciones no gubernamentales para poner en marcha igualmente dichos proyectos de desarrollo humano.

La cooperación internacional no es, ni puede ser, la solución al problema del subdesarrollo latinoamericano, pero difícilmente podrá encontrarse una solución a dicho problema sin la cooperación internacional. La inversión en desarrollo humano es una de las inversiones más rentables, al margen de ser claramente solidaria por cuanto se focaliza directamente en individuos concretos. Canalicemos pues el esfuerzo de la cooperación internacional hacia el desarrollo humano; puede que ello no saque a la región del subdesarrollo, si no va acompañada de otras actuaciones, pero al menos sacará de la pobreza a muchos latinoamericanos y no se podrá afirmar que los recursos no se emplearon correctamente.

\section{Bibliografía}

Anima Puentes, S. y Guerrero Flores, V., (2003), Economía mexicana y reforma estructural 1982-2003. Elementos para comprender la transición, México, Facultad de Economía, UNAM.

Bulmer-Thomas, V. (comp.), (1996), El nuevo modelo económico en América Latina. Su efecto en la distribución del ingreso y en la pobreza, México, Fondo de Cultura Económica, edición española en 1997.

CEPAL, (1990), Transformación productiva con equidad. La tarea prioritaria del desarrollo de América Latina y el Caribe en los años noventa, Santiago, CEPAL. 
-(2004-a), Anuario Estadístico de América Latina y el Caribe 2003, Santiago, CEPAL.

-(2004-b), Estudio Económico de América Latina y el Caribe 2003-2004, Santiago, CEPAL.

Edwards, S., (1995), Crisis y reforma en América Latina. Del desconsuelo a la esperanza, Buenos Aires, Emecé, edición española en 1997.

Fallas Venegas, H., (1983), “Crisis económica y transformación social en Costa Rica”, en J. RoviRa MAS (comp.), Costa Rica hoy: la crisis y sus perspectivas, San José, EUNED, pp. 57-82.

Graciarena, J., (1976), "Poder y estilos de desarrollo: una perspectiva heterodoxa", Revista de la CEPAL, $\mathrm{n}^{\mathrm{O}} 1$.

Hidalgo CaptTán, A. L., (1998), El pensamiento económico sobre desarrollo. De los mercantilistas al PNUD, Huelva, Servicio de Publicaciones de la Universidad de Huelva.

- (2003), Costa Rica en evolución. Política económica, desarrollo y cambio estructural del sistema socioeconómico costarricense (1980-2002), San José, Editorial Universidad de Costa Rica y Servicio de Publicaciones de la Universidad de Huelva.

PINTo, A., (1976), "Notas sobre los estilos de desarrollo en América Latina", Revista de la CEPAL, $\mathrm{n}^{\mathrm{o}} 1$.

PNUD, (2004), Informe sobre desarrollo humano 2004, Madrid, Mundi-Prensa.

PorTer, M. E., (1990), La ventaja competitiva de las Naciones, Barcelona, Plaza y Janés, edición española de 1991.

PreBISCH, R., (1949), "El desarrollo de América Latina y algunos de sus principales problemas", en El Trimestre Económico, Vol. 16, n 63.

SunkEL, O. y PAZ, P., (1970), El subdesarrollo latinoamericano y la teoría del desarrollo, Madrid, Siglo XXI.

TalaVera Déniz, P., (1986), “Tipología de las formaciones sociales capitalistas periféricas (I): Economías de subsistencia y Economía primario-exportadoras", en E. Palazuelos Manso (coord.), Las economías capitalistas durante el período de expansión 1945-1970, Madrid, Akal, pp. 280-298

VAlEnZUela, J., (1986), El capitalismo mexicano en los ochenta, México, ERA. 